\title{
Transit Ridership Efficiency as a Function of Fares
}

\author{
Gerrit R. Moore
}

\begin{abstract}
$\overline{\text { Abstract }}$
The purpose of this study is to assist in the development of transit fare policies that exploit the benefits of public transit in the mix of transportation options for Washington State. The study relates fares to ridership performance, fare-box recovery; and system utilization.

Ridership efficiency, a measure of transit performance, is estimated for 24 State transit systems. A mathematical model is developed that relates fares to ridership efficiency: The ridership efficiency function follows the complement of a cumulative normal probability distribution. The tail of the distribution is reached at $\$ 0.95$. Higher fares have little impact on ridership efficiency. An operating cost model to estimate the fare-box recovery and operating cost subsidy is developed. Ridership, fare-box recovery, and system utilization estimates are made for selected transit systems.
\end{abstract}

\section{Introduction}

The purpose of this study is to examine transit ridership (unlinked trips) as a function of fares to provide a more informed basis for establishing transit fare policies. In conjunction with an examination of ridership is an examination of operating cost as a function of ridership and the consequent changes in revenues with changes in fares and ridership. The capture of trips from other transportation modes and the provision of additional travel opportunities by increasing transit ridership provides the societal benefits of reduced pollution, global warming, congestion mitigation. and, as described by Burkhardt (1998), economic development. 


\section{Background}

In 1998, Washington State provided support of public transit by a sales tax increment levied by the local transit district and an increment of the locally raised motor vehicle excise tax. The State had no requirement for a minimum fare-box recovery, leaving transit districts free to set fare policies that best reflected the community needs. Consequently, Washington State public transit systems reflected a total range of fares from fare-free to the generally accepted urban fare levels. This provided the investigator with a dataset covering a full range of fares as applied to fairly uniform market ethos.

The thrust of most investigations is to improve the fare-box contribution to meeting operating costs rather than finding a balance between fares and overall community benefits. LaBelle and Fleishman (1997) discuss various fare options but only address ridership impacts in an anecdotal manner. They note, "Ridership increases of $20-40 \%$ have been seen with free fares .... however, that such a policy does not by itself generate long-term increases in ridership, but loses considerable revenue as well." On the other hand, King, Garrick, and Ravishanker (1998) describe the first three years' impact of a fare-free policy on fare elasticity (by shrinkage ratio) for a midsized Connecticut bus service as being $-0.66,-1.16$, and -1.08 , respectively. This indicates a sustained ridership increase in the first three years.

Generally, investigators (Linsalata and Pham 1991) have identified values of fare elasticity varying from -0.12 to -1.18 . These studies mostly have been longitudinal. That is, they have examined single transit systems with relatively small fare changes over limited durations. This has the advantage of studying a system with consistent marketing methods in a defined community. However, these studies have the disadvantage of examining a narrow range of fares and might miss regions of high volatility where blocks of rider population choose or reject transit over time on the basis of fares.

\section{The Models}

This section describes the mathematical model developed for ridership efficiency as well as the operating cost model to estimate the operating cost fare-box recovery model. The source data for this study are given in Table 1. 


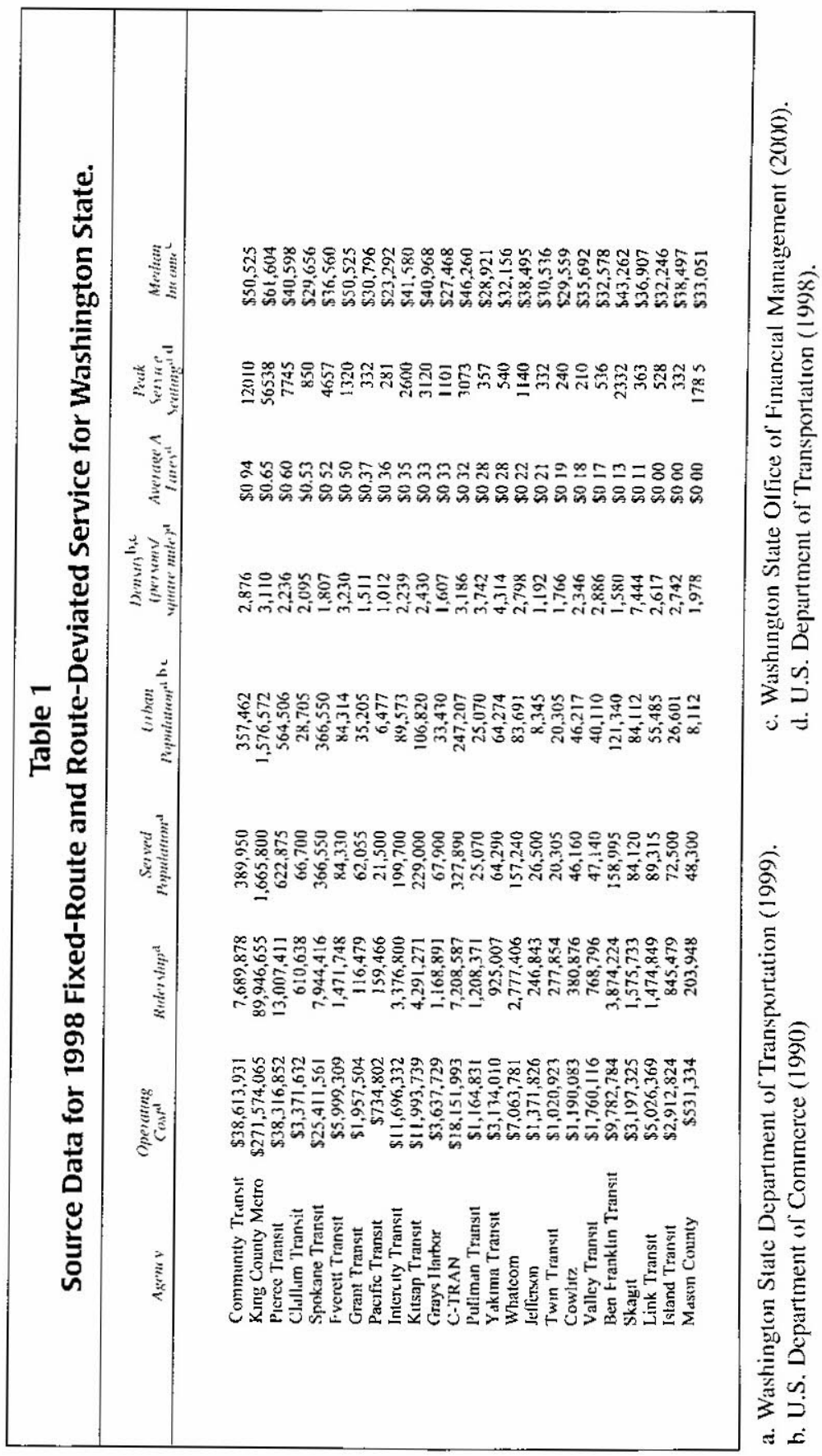




\section{Ridership Efficiency}

Ridership efficiency is a parameter for relating the performance of 24 Washington State transit systems by community characteristics. It is a measure of transit system efficiency in capturing transportation mode share (ridership) in a given community. Ridership efficiency is the ratio of ridership to community population, transit service investment, and median income (each raised to a fractional exponent). This permits direct estimation of ridership based on the community characteristics and fare price. Ridership efficiency is defined by Equation 1.

$$
R_{e}=R /\left(S R_{I} P_{u} R_{2} I_{m} R_{3 A_{0}}\right)=F(\text { fares }),
$$

where:

$\begin{array}{ll}R_{e} & \text { is the ridership efficiency. } \\ R & \text { is annual ridership (unlinked trips). } \\ S & \text { is service infrastructure (number of seats during peak } \\ & \text { service). } \\ P_{u} & \text { is the urban population in the service area. } \\ A_{0} & \text { is the constant of proportionality. } \\ R_{l}, R_{2}, \text { and } R_{3} & \text { are constants determined by a least the squares analysis. } \\ I_{m} & \text { is the household median income for the service area. } \\ F \text { (fares) } & \text { is fares function, which models ridership efficiency as a } \\ & \text { function of average fares. }\end{array}$

The complicated fare pricing policies with zone pricing, congestion pricing, transfers, etc.. have been simplified by using the annual fare-box revenue divided by annual ridership. The resulting variable is average fares. Fare-box revenue applies to revenues generated at the fare box or daily payment and not pass subscription or other means of payment. The significance of that variable lies in the transit-using public's perception of cost.

Service infrastructure $(S)$ is the capacity of the system to meet the ridership demand of the population $\left(P_{u}\right)$. The studies referenced above generally use revenue service miles for the measure of service infrastructure. Here, system 
peak-seating capacity is the measure of infrastructure investment. It allows the aggregation of data from different transit modes (i.e., bus, light rail, and heavy rail). It also allows the evaluation of system utilization, the number of unlinked trips per seat per year, which is a measure of transit system efficiency.

The more people in an area, the greater demand on all modes of transportation, including transit. The urban population $\left(P_{u}\right)$ in the service area is a function of ridership. In this study, the population of those jurisdictions and Census Designated Places (CDPs) within the service area with densities greater than 1,000 persons per square mile is the urban population of that area.

Lower-income households are less likely to afford choices between transportation modes. Therefore, household median income $\left(I_{m}\right)$ as the income of the 50 th percentile has a strong influence on that choice. Median income represents the income of that population segment most likely to use transit.

The constant of proportionality $\left(A_{0}\right)$ and the fare functions are determined as a part of the data analysis described below.

The ridership efficiency variables $\left(S, P_{w}\right.$ and $\left.I_{m}\right)$ are raised to powers of fractional exponents $-R_{1}, R_{2}$, and $R_{3}$ - to limit the mutual dependencies that they might have. System peak seating capacity $(S p)$ in a transit system, while generally a management decision based on external factors such as available tax subsidy or political activity, is related closely to the service area population. Generally, the higher population areas offer higher income jobs than the lower population areas so median income might also be related to population. The values of $R_{1}, R_{2}$, and $R_{3}$ are found through a least squares analysis described below. The fares function of ridership efficiency is:

$$
R_{e}=F(\text { fares })=B_{1} \exp \left(B_{2} F^{B_{3}}+B_{4}\right)
$$

where:

$F$

$\exp (\mathrm{f})$

$B_{1}, B_{2}, B_{3}$, and $B_{4}$ are constants determined in the least squares fitting operation of Equation (2) to the transit data reduced by Equation (1). 
Equation (2) fits a wide range of geometries from linear functions to cumulative probability distributions. The constraint this function places on the data analysis process is that if $B_{2}$ is negative, the dependent variable (demand) is a monotonically decreasing function of the independent variable (price). This is consistent with general economic understanding.

The regression constants $\left(R_{n}\right.$ and $\left.B_{n}\right)$ are determined with a PC spreadsheet application program (Corel Quattro Pro 6.0 1996). The regression begins with an assumption that in Equation (1) the exponents $R_{1}$ and $R_{2}$ equal 1.0 and $R_{3}$ equals -1.0. An array of trial $R_{e} \times A_{0}$ values for Equation (1) is calculated. The array is divided by the average of $R_{e} \times A_{0}$ for the fare-free transits, which is the constant of proportionality, $A_{0}$. This gives a value of one for $R_{e}$ where the average fare $(F)$ is zero. The $R_{e}$ array is fitted to the $F$ (fares) equation [Equation (2)] by an ordinary least squares process with the selection of $B_{n}$ and $R_{n}$ constants. The spreadsheet program feature for finding optimum solutions for linear and nonlinear problems is used. Here, the optimum solution is the minimum of the sum of the squares of the residuals between the model values and input array for $R_{e}$, for each value of $F$. A sample standard deviation for the regression is calculated. Datasets with residuals exceeding two standard deviations are deleted and the process is repeated with the reduced dataset.

The result of this regression is a function that is unity where $F$ is zero, and decreases as the $F$ values increase. This suggests that ridership efficiency $\left(R_{e}\right)$ is the probability that a person from the transit-using population will choose transit if the fare price is equal to or less than a given value.

There is a choice between two models for evaluating this probability statement. The first model, the monetary concept, considers the probability of choosing transit as dependent only on the fare price not exceeding a given value. The second model. the confrontational concept, has two components. It considers the probability of choosing transit as being conditional on the confrontational act of fares being demanded, and then, on the fare price not exceeding a given value. This concept has been described as the "psychological costs associated with the fare box" (Hodge, Orrell III, and Strauss 1994). There is a difference in the way the data processing is approached for each concept.

With the monetary model, the regression includes the $\$ 0.00$ fare subset. With the confrontational model, the regression of ridership efficiency does not 
include the $\$ 0.00$ fare subset because the confrontational component lies along the zero-fares axis. The difference between the average of the zero fares $R_{e}$ values (in this case, unity) and the intersection of the regression with the $\$ 0.00$ fare axis is the estimate of the demand loss because of the confrontational aspect of the fare box.

Table 2 shows the results of the regressions for each model. The sample standard deviation for the confrontational model is 0.023 with 17 data samples. The sample standard deviation for the monetary model is 0.036 with 18 data samples. Here, two of the zero fares dataset are included. The rejected datasets are the same for both regressions except that an additional greater-than-zerofares set and a zero fares set are rejected with the monetary model. The most probable thesis is one that provides the best data fit, which is the confrontational model. The $R_{e}$ independent variable exponents are the elasticities of the respective variables on $R_{e}$ and $\mathrm{R}$. The exponent of median income, $R_{3}$, is significantly less than the other $R_{e}$ exponents, suggesting that a useful model might be based on $R, S$, and $P_{u}$ alone. This is shown in Table 2 under Confrontational $b$ where the exponent is set to zero, forcing the median income term to unity.

\begin{tabular}{|c|c|c|c|c|}
\hline \multicolumn{5}{|c|}{$\begin{array}{c}\text { Table } 2 \\
\text { Constants from Ridership Efficiency Regression }\end{array}$} \\
\hline \multirow[b]{2}{*}{$\begin{array}{c}\text { Constants } \\
F(f)\end{array}$} & \multicolumn{4}{|c|}{ Controntational } \\
\hline & Monetary & $a$ & $b$ & \\
\hline$B_{l}$ & 21.80633 & 0.41351 & $0.41673]$ & \\
\hline$B_{2}$ & -004173 & -5.59248 & -5.60035 & \\
\hline$B_{3}$ & 0.587121 & 3.26618 & 3.31952 & \\
\hline$B_{4}$ & -20.80716 & 0.17368 & 0.17597 & \\
\hline$R e$ & & & & \\
\hline$R_{1}$ & 0.85538 & 0.79561 & 0.79134 & (peak seats) \\
\hline$R_{2}$ & 0.50837 & 0.50078 & 0.48739 & (population) \\
\hline$R_{3}$ & -029348 & 0.10864 & 01 & (median income) \\
\hline$A_{0}$ & 54591 & 134.461 & 50651 & \\
\hline Ssigma & 0.03564 & 0.02266 & 0.02380 & \\
\hline
\end{tabular}

a This value is set at zero to force the median income vanable to unity. 
The constants in Equation (2) can be interpreted as:

- $B_{I}$ is the probability that transit is chosen if a fare box demand is made.

- $B_{2}$ and $B_{3}$ define the shape of the ridership/fares probability distribution.

- $B_{4}$ is the minimum probability that transit will be chosen if fares are demanded (no matter how expensive, at least within the universe of existing fares experience).

Table 3 lists the results of the regression using the confrontational model. Figure 1 is a plot of those data. The figure illustrates four regions of fares impact on ridership efficiency:

- The first region is along the zero-fares axis where the ridership efficiency changes with the confrontation of fare demand. This is defined by the $B_{l}$ term in Equation (2).

- The second region extends from $\$ 0.00$ to $\$ 0.20$ average fares. Ridership is fairly insensitive to fare changes (everyone has two dimes or a quarter).

- The third region extends from $\$ 0.20$ to $\$ 0.95$. Here, ridership is very sensitive to the average fares charged.

- The fourth region, the toe of the curve, extends beyond $\$ 0.95$. The slope is nearly zero. People seem willing to pay any fare demanded. Here, patrons either consider the fare costs as a part of the employment investment or they do not have the means to invest in other transportation options. This region is defined by the $B_{4}$ term in Equation (2).

The third and fourth regions in the fare function are suggested by Boyle (1985) and quoted in Linsalata and Pham (1991): 
Table 3

Confrontational Ridership Efficiency Model

(with Seats, Population, and Median Income as

Independent Variables of $\boldsymbol{R}_{e}$ )

Sample Size $=17$

Sample Standard Deviation $=0.02266$

\begin{tabular}{|c|c|c|c|c|c|}
\hline Agency & $\begin{array}{c}\text { Average } \\
\text { Fares } \\
\end{array}$ & $\begin{array}{c}R_{e} \\
\text { Input } \\
\text { Data } \\
\end{array}$ & $\begin{array}{c}R_{e} \\
\text { Model } \\
\text { Estimate }\end{array}$ & $\begin{array}{c}\text { Residuals } \\
(\sigma)\end{array}$ & $\begin{array}{c}\text { WashDOT } \\
\text { Class }\end{array}$ \\
\hline Community Transit & $\$ 0.94$ & 0.16464 & 0.17764 & -0.14 & Urbanized \\
\hline King County Metro & $\$ 0.65$ & 0.25512 & 0.28114 & 0.35 & Urbanized \\
\hline Pierce Transit & $\$ 0.60$ & 0.30130 & 0.31413 & 0.48 & Urbanized \\
\hline Clallam Transit & $\$ 0.53$ & 0.38824 & 0.37723 & 0.13 & Rural \\
\hline Spokane Transit & $\$ 0.52$ & 0.34345 & 0.38402 & -0.83 & Urbanized \\
\hline Everett Transit & $\$ 0.50$ & 0.43417 & 0.40542 & -0.29 & Urbanized \\
\hline Grant Transit $^{\mathrm{a}}$ & $\$ 0.37$ & 0.15104 & 0.50349 & -16.08 & Rural \\
\hline Pacific Transit & $\$ 0.36$ & 0.51971 & 0.50978 & -0.77 & Rural \\
\hline Intercity Transit & $\$ 0.35$ & 0.51087 & 0.51694 & -0.45 & Small city \\
\hline Kitsap Transit & $\$ 0.33$ & 0.50921 & 0.52772 & -0.82 & Small city \\
\hline Grays Harbor & $\$ 0.33$ & 0.54432 & 0.52993 & 0.64 & Rural \\
\hline C-TRAN & $\$ 0.32$ & 0.57630 & 0.53374 & 1.88 & Urbanized \\
\hline Pullman Transit ${ }^{2}$ & $\$ 0.28$ & 1.24438 & 0.55304 & 30.50 & Rural \\
\hline Yakima Transit & $\$ 0.28$ & 0.55664 & 0.55417 & 0.11 & Small city \\
\hline Whatcom $^{2}$ & $\$ 0.22$ & 0.82406 & 0.57098 & 11.17 & Small city \\
\hline Jefferson & $\$ 0.21$ & 0.60534 & 0.57268 & 1.44 & Rural \\
\hline Twin Transit & $\$ 0.19$ & 0.56244 & 0.57660 & -0.62 & Rural \\
\hline Cowlitz & $\$ 0.18$ & 0.57970 & 0.57818 & 0.07 & Small city \\
\hline Valley Transit & $\$ 0.17$ & 0.59060 & 0.57956 & 0.49 & Rural \\
\hline Ben Franklin Transit & $\$ 0.13$ & 0.54696 & 0.58438 & -1.65 & Small city \\
\hline Skagit $^{\mathrm{a}}$ & $\$ 0.11$ & 1.15509 & 0.58540 & 25.14 & Rural \\
\hline Link Transit & $\$ 0.00$ & 0.97286 & & & Rural \\
\hline Island Transit & $\$ 0.00$ & 1.18982 & & & Rural \\
\hline Mason County & $\$ 0.00$ & 0.83732 & & & Rural \\
\hline
\end{tabular}

a. Rejected dataset because residual is greater than two standard deviations

A second interesting point concerns the concept of a fare threshold. This concept postulates that, as fare rises beyond a certain threshold level, ridership behavior changes significantly. [...] Elasticities are increasingly negative at higher values of the original fare up to the "over 60 cents" category. In this category ridership response become less elastic than the "51 cents to 
60 cents" category: The explanation driving this version would be that by the time a relatively high fare level is reached, most of the "choice" riders have already abandoned transit for another mode, and so further increases have less impact on ridership. While the data in Table 1 does not provide conclusive proof that a fare threshold of this nature actually exists, further research into this concept would be useful.

Figure 1 shows the less elastic response region begins at $\$ 0.95$ rather than S0.60. Using the Consumer Price Index ratio for 1984 to 1998 as a deflator, the $1984 \$ 0.60$ becomes $\$ 0.96$ in 1998 dollars (U.S. Department of Commerce 1999 , p. 882)

$R_{e}$ follows a cumulative normal distribution, which supports the thesis that the transportation mode choice can be represented as a probability function. This is tested by substituting the complement of the cumulative normal distribution function, which is available in spreadsheet application programs, for the $\exp (\mathrm{f})$ term in the least squares process for Equation (2). The normal distribution function has a nearly identical fit to the data as Equation (2), with a sample standard distribution of 0.02283 . The resulting normal distribution has a mean of $\$ 0.525$ and a standard deviation of $\$ 0.183$. The values $B_{1}$ and $B_{4}$ are the same. The impact on ridership with a fares change might be estimated from a Cumulative Normal Distribution table. The continuity of the $R_{e}$ function over the range of fare prices suggests that the function is independent of system size.

The transit agencies listed in Table 3 that charge the highest fares serve the highly urbanized regions. These regions have the greatest congestion and the most limited parking. Transit agencies charging the lower fares serve communities with no congestion and the easiest parking. Yet, these are the transit agencies with the highest ridership efficiency. Therefore, the examination of such typical cross products as congestion and parking costs is not relevant to this study.

Figure 1 shows four transit systems that fall outside the two standard deviation bounds for the regression. The first is Skagit Transit at \$0.11. This is essentially a fare-free transit (13 routes) except for 2 commuter routes. One commuter route is to the Boeing plant in Everett, which requires the purchase 


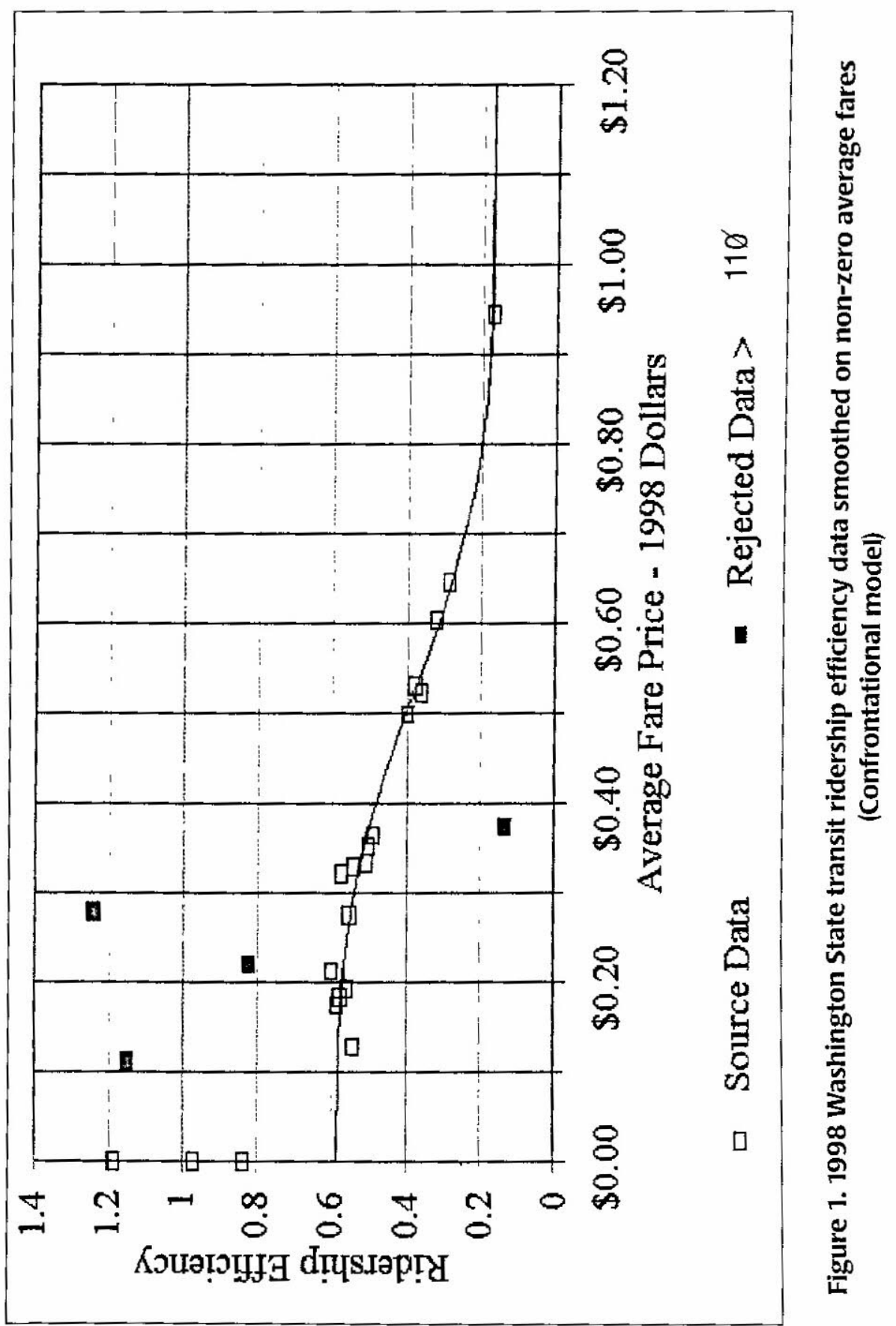


of a monthly pass. The other is a contracted service for a Seattle City Light generating facility. It is a fare-free service for passengers. Two other systems, Whatcom $(\$ 0.22)$ and Pullman $(\$ 0.28)$, provide prepaid service to state universities through the use of university passes. This is a free good to the university transit user. It suggests that in special cases, the pass is a way of avoiding the confrontational effect of charging fares.

Informal estimates of pass-based ridership for Whatcom and Pullman are about 40 percent and 90 percent, respectively. $B_{I}$ can be adjusted by the pass fraction as:

$$
B_{1}{ }^{\prime}=B_{1}+\left(1-B_{I}\right) P
$$

where:

$B_{I}{ }^{\prime} \quad$ is the adjusted $B 1$ value.

$P \quad$ is the fraction of trips made using the pass system.

Using these pass estimates, the model estimate for ridership efficiency becomes 0.895 for Whatcom, which is within 3.13 standard deviations of the input data, and 1.26 for Pullman, which is within 0.64 standard deviations.

The fourth out-of-bounds system is Grant Transit ( $\$ 0.37)$. Grant Transit, a new system started in 1996, serves a very rural county in eastern Washington that has very little transit experience.

\section{Estimation Error for Ridership}

The sample standard deviations for the regressions given above relate only to the quality of fit of $R_{e}$ data to Equation (2). The quality of fit between ridership input data (Table 1 ), and the $F$ (fares) function and the community variables (Table 1 ) is evaluated by solving for $\ln R$ from a logarithmic transform of Equation (1) and calculating the residuals. Thus,

$$
\Delta r_{n}=\ln R\left(\text { datum }_{n}-\ln (R)_{n}\right.
$$


where:

In $R$ (datum $)_{n}$ represents the logarithm of the $n$th ridership datum from Table 1.

$\ln (R)_{n} \quad$ denotes the logarithm of the ridership calculation from the community characteristics (Table 1) and $R_{e}$ (Table 3 ) for the $n$th fare set.

$\Delta r_{n} \quad$ is the residual between the logarithm of the ridership datum and the logarithm of the fares model.

The mean and sample standard deviation of the residuals is calculated from the fares array of residuals of the resulting dataset. There are 10 degrees of freedom ( 15 datasets and 4 independent variables). The residual mean is 0.00151 , which is negligible for this type of analysis. The residual sample standard deviation is 0.044 , or 4 percent in estimating ridership.

\section{Fare Elasticity}

A more conventional way of looking at the change in ridership with a change in fare price is with the economic concept of elasticity (Linsalata and Pham 1991). The three different measures of elasticity can be defined by average fare $(F)$ and ridership efficiency $\left(R_{e}\right)$.

Point elasticity

$$
\epsilon_{p t}=\frac{\partial R}{\partial F} \cdot \frac{F}{R}=B_{2} \cdot B_{3} \cdot F^{B^{3}} \cdot\left(\frac{R_{e}-B_{4}}{R_{e}}\right)
$$

Midpoint elasticity

$$
\epsilon_{\text {mid }}=\frac{\Delta R}{\Delta F} \cdot \frac{F}{R}=\frac{R_{e n}-R_{e n-1} \cdot\left(F_{n}+F_{n-1}\right)}{R_{e}+R_{e n-1} \cdot\left(F_{n}-\left(F_{n-1}\right)\right.}
$$

Constant arc elasticity

$$
\epsilon_{\operatorname{arc}}=\frac{\ln R_{e n}-\ln R_{e n-1}}{\ln F_{n}-\ln F_{n-1}}
$$


where:

the subscript, $n$, denotes the $n$th dataset.

Figure 2 contains plots of these elasticities. A 30 percent fare change is assumed for the midpoint and constant arc elasticities. While numerical values of the midpoint and constant arc elasticities at a fare price are different, they are close enough to essentially lie over each other in this plot. This suggests that the midpoint and constant arc elasticities are equivalent for practical data processing purposes. The literature (Linsalata and Pham 1991) cites values for elasticity ranging from -0.12 to -1.18 , while Figure 2 shows values ranging from 0 to -1.63. The elasticities in Figure 2 are representative of the total annual ridership change, independent of time. Elasticity along the zero-fares axis (the confrontational loss) is indeterminate.

Fare elasticity is a function of the average fare $(F)$ price and has meaning in that context. It is often discussed in terms of the size of the transit system, but this analysis shows that it is the average fare price that is critical.

\section{Operating Cost Model}

An operating cost model is required to evaluate the fiscal impacts of ridership changes. Transit operating cost models generally employ vehicle miles or revenue service miles as the independent variable. Operating distance captures the labor and energy costs, the major cost elements in operating a transit system. To relate those variables to ridership $(R)$ or ridership efficiency $\left(R_{e}\right)$ in a general way. surrogates for operating distance are used. Surrogates include population density $(D)$. persons per square mile for service area, system peak seating capacity $(S)$, and ridership $(R)$. The operating cost model is given in Equation (8).

$$
C=C_{0} S^{C_{1 D} C_{2 R} C_{3}}
$$

where:

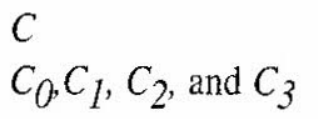

$D$ is operating cost.

are constants determined in the least squares fitting operation.

is population density (persons per square mile) for service area. 


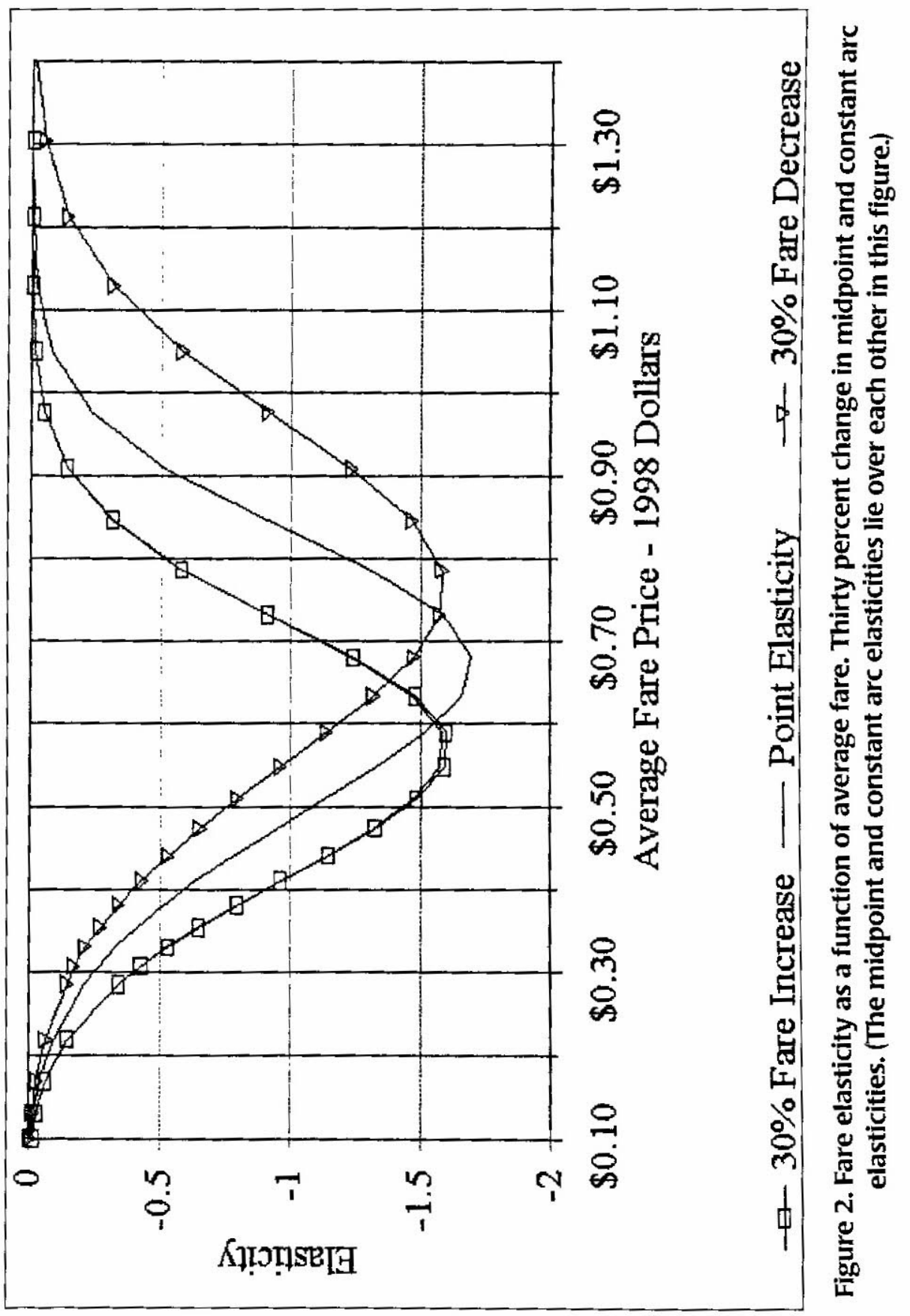


The constants are determined by a regression from the 1998 data listed in Table 1. As with the ridership efficiency regression, this regression is determined with a PC spreadsheet application program. The regression begins with an assumption that exponents $C_{1}$ and $C_{3}$ equal 1.0 and $C_{2}$ equals -1.0 . A model array [(Equation (8)] is fitted to the input cost data by an ordinary least squares process with the selection of $C_{n}$ constants. The spreadsheet program feature for finding optimum solutions for linear and nonlinear problems is used as with the $R_{e}$ process, described above. Here, the optimum solution is the minimum sum of the squares of the residuals between the model values and input data $C$. A sample standard deviation for the regression is calculated. Datasets with residuals exceeding two standard deviations are deleted and the process is repeated with the reduced dataset.

Three fare-collecting transits are not included in this set because the residuals are greater than two sample standard deviations. Results of the operating cost regression are given in Table 4. In addition, the operating costs per person (operating cost divided by served population shown in Table 1) and subsidy per person (the difference between operating costs and fare-box income, divided by served population) show the relative cost and tax burden carried by the service area populations. These data indicate that lower fare transit systems impose a lower per capita financial burden on their service areas than higher fare systems.

\section{Estimates}

Equations (1), (2), and (3) permit ridership and fiscal estimates for transit systems as functions of average fare price. The methodology is described below and estimates are made for transits serving urban, small city and rural communities.

\section{Methods}

The models described above provide unbounded estimates of ridership and operating costs. They are not tempered by the political realities of capital investment and operating cost limits, and the effect of crowding and minimum loading of transit vehicles (the "empty-bus" syndrome). These limitations impact how the transit infrastructure accommodates passenger loads. The lag time of ridership changes with fare policy changes is not treated by these models.

Table 5 presents system utilization for three intensely used transit systems in the United States and King County Metro (U.S. Department of 


\section{Table 4 \\ Operating Cost Model (Seats, Density, and Ridership as Independent Variables)}
Results:
$\mathrm{C}_{0}=280.5100$ (constant)
$\mathrm{C}_{1}=0.5343$ (seats)
$C_{2}=-0.0562$ (density)
$\mathrm{C}_{3}=0.4580$ (ridership)

Sampie size $=20$

Deg. Of frdm $=14$

Residual sample ${ }_{-}=\$ 670,609$

Residual mean $=\$ 82,742$

\begin{tabular}{|c|c|c|c|c|c|}
\hline Agency & $\begin{array}{c}1998 \text { Operating } \\
\text { Cost }\end{array}$ & $\begin{array}{c}\text { Cost } \\
\text { Model }\end{array}$ & $\begin{array}{c}\text { Residuals } \\
(\sigma)\end{array}$ & $\begin{array}{c}\text { Cost per } \\
\text { Person } \\
\end{array}$ & $\begin{array}{c}\text { Subsidy per } \\
\text { Person }\end{array}$ \\
\hline Community Transit & $\$ 38,613,931$ & $\$ 38,643,973$ & -0.045 & $\$ 99.02$ & $\$ 80.39$ \\
\hline King County Metro & $\$ 271,574,065$ & $\$ 271,521,973$ & 0.078 & $\$ 163.03$ & $\$ 128.10$ \\
\hline Pierce Transit & $\$ 38,316,852$ & $\$ 39,445,191$ & -1.683 & $\$ 61.52$ & $\$ 48.89$ \\
\hline Clallam Transit & $\$ 3,371,632$ & $\$ 2,995,418$ & 0.561 & $\$ 50.55$ & $\$ 45.69$ \\
\hline Spokane Transit & $\$ 25,411,561$ & $\$ 24,269,186$ & 1.703 & $\$ 69.33$ & $\$ 57.98$ \\
\hline Everett Transit & $\$ 5, \overline{999,309}$ & $\$ 5,533,603$ & $0 . \overline{694}$ & $\$ 71.14$ & $\$ 62.42$ \\
\hline Grant Transit & $\$ 1,957,504$ & $\$ 863,767$ & 1.631 & $\$ 31.54$ & $\$ 30.84$ \\
\hline Pacific Transit & $\$ 734,802$ & $\$ 933,031$ & -0.296 & $\$ 34.18$ & $\$ 31.47$ \\
\hline Intercity Transit & $\$ 11,696,332$ & $\$ 11,869,298$ & -0.258 & $\$ 58.57$ & $\$ 52.60$ \\
\hline Kitsap Transit ${ }^{a}$ & $\$ 11,432,527$ & $\$ 14,520,467$ & -4.605 & $\$ 49.92$ & $\$ 43.67$ \\
\hline Grays Harbor & $\$ 3,637,729$ & $\$ 4, \overline{699,622}$ & -1.583 & $\$ 53 . \overline{57}$ & $\$ 47.90$ \\
\hline C-TRAN & $\$ 18,151,993$ & $\$ 18,007,546$ & 0.215 & $\$ 55.36$ & $\$ 48.28$ \\
\hline Pullman Transit ${ }^{a}$ & $\$ 1,164,831$ & $\$ 2,953,044$ & -2.667 & $\$ 46.46$ & $\$ 33.03$ \\
\hline Yakima Transit & $\$ 3,134,010$ & $\$ 2,730,171$ & 0.602 & $\$ 48.75$ & $\$ 44.78$ \\
\hline Whatcom & $\$ 7.063 .781$ & $\$ 6,890,243$ & 0.259 & $\$ 44.92$ & $\$ 41.03$ \\
\hline Jefferson Transit & $\$ 1,371,826$ & $\$ 1,234,724$ & $0 . \overline{204}$ & $\$ 51.77$ & $\$ 49.78$ \\
\hline Twin Transit & $\$ 1,020,923$ & $\$ 1,072,971$ & -0.078 & $\$ 50.28$ & $\$ 47.64$ \\
\hline Cowlitz Transit & $\$ 1,190,083$ & $\$ 1,136,073$ & 0.081 & $\$ 25.78$ & $\$ 24.27$ \\
\hline Valley Transit & $\$ 1,760,116$ & $\$ 2,554,236$ & -1.184 & $\$ 37.34$ & $\$ 34.49$ \\
\hline Ben Franklin ${ }^{a}$ & $\$ 9,782,784$ & $\$ 12,162,069$ & -3.548 & $\$ 61.53$ & $\$ 58.41$ \\
\hline Skagit Transit & $\$ 3,197,325$ & $\$ 2, \overline{731}, \overline{282}$ & 0.695 & $\$ 38.01$ & $\$ 35.92$ \\
\hline $\operatorname{Link}^{\mathrm{a}}$ & $\$ 5,026,369$ & $\$ 3,435,258$ & 2.373 & $\$ 56.28$ & $\$ 56.28$ \\
\hline Island Transit & $\$ 2,912,824$ & $\$ 2,070,819$ & 1.256 & $\$ 40.18$ & $\$ 40.18$ \\
\hline Mason County & $\$ 531,334$ & $\$ 789,970$ & -0.386 & $\$ 11.00$ & $\$ 11.00$ \\
\hline Averages & & & & $\$ 54.58$ & $\$ 48.13$ \\
\hline
\end{tabular}

a Rejected dataset because residual is greater than two standard deviations. 


\begin{tabular}{|lc|}
\hline & $\begin{array}{c}\text { Table 5 } \\
\text { Transit Utilization 1994 }\end{array}$ \\
\hline Transit System & Rides/Seat/Year \\
\hline San Francisco & 6,844 \\
Washington, D.C. (WMATA) & 6,598 \\
NYC (NYCTA) & 5,125 \\
King County METRO (Seattle) & 1,600 \\
\hline
\end{tabular}

a. 1994 Data Tables and Transit Profiles, FTA.

Transportation 1995). System utilization is the ratio of annual ridership to the number of seats in maximum service. The unit description is the number of rides per seat per year. At the high end, it is a measure of crowding, and at the low end, it is a measure of vehicle emptiness.

Fare-box recovery is commonly used to evaluate transit financial performance. It is the percent contribution that passenger fares make to the operating cost and is calculated by dividing the product of the average fare and the ridership estimate by the operating cost.

Fare-box revenue, the product of average fare and ridership, has two maxima as a function of fare value. The maxima are directly derived from ridership efficiency, so they are the same for any transit system. The first occurs at about $\$ 0.50$ and the second occurs at some fare value greater than $\$ 1.20$. The latter maximum occurs because ridership is independent of fare value beyond the S0.96 value, so fare-box revenue increases linearly with fares.

In the following examples, ridership is estimated by solving Equation (1). This provides an unbiased estimate that assumes the data variations about $R_{e}$ are random. Another way of estimating would be to assume the variations about $R_{e}$ are not random. In this case, the estimate for a particular transit is made from the $R_{e}$ function with the ridership datum as the point of departure. Ridership is estimated as the product of $R_{e}$ and the ratio of the input ridership to the ridership efficiency at that average fare.

\section{Examples}

The Washington State Department of Transportation classes transit systems according to the type of community served: urban, small city, and rural. 
The following sections reflect these classifications and are, respectively, King County Metro (Seattle), Kitsap (Bremerton and Poulsbo), and Mason County. The estimates are based on the 1998 models for ridership [Equation (1)] and cost [Equation (8)]. They project what might have happened in 1998 with the particular agencies under different fare policies.

King County Metro. King County Metro serves 269 routes in the most populated county in Washington State. The 1998 per zone base fare is $\$ 1.25$ peak hours, and $\$ 1.00$ off peak. There are two zones with fares: the City of Seattle and the rest of King County. A fare-free zone covers the commercial center of Seattle. The 1998 average fare for King County Metro is S0.65.

Figure 3 shows the ridership and fare-box performance estimates for King County Metro. With a S0.65 average fare price, ridership for King County Metro is only about a third of its potential. If the average fare price decreased, there would be significant increases in ridership with a potential of over 180 million rides and perhaps as high as 300 million rides. On the other hand, any increase in average fare price beyond $\$ 0.95$ would result in only a 37 percent decrease in ridership.

Table 6 lists selected King County Metro Transit performance estimates. The table shows the utilization (ridership per seat) for $\$ 0.00$ average fare is less than

\begin{tabular}{|ccrrrrr|}
\hline \multicolumn{8}{|c|}{$\begin{array}{c}\text { Table } 6 \\
\text { King County }\end{array}$ Metro Transit Performance Estimates with Constant } \\
Service or Utilization
\end{tabular}

a. Fare for first revenue maximum.

b. 1998 actual as erage fare value. 


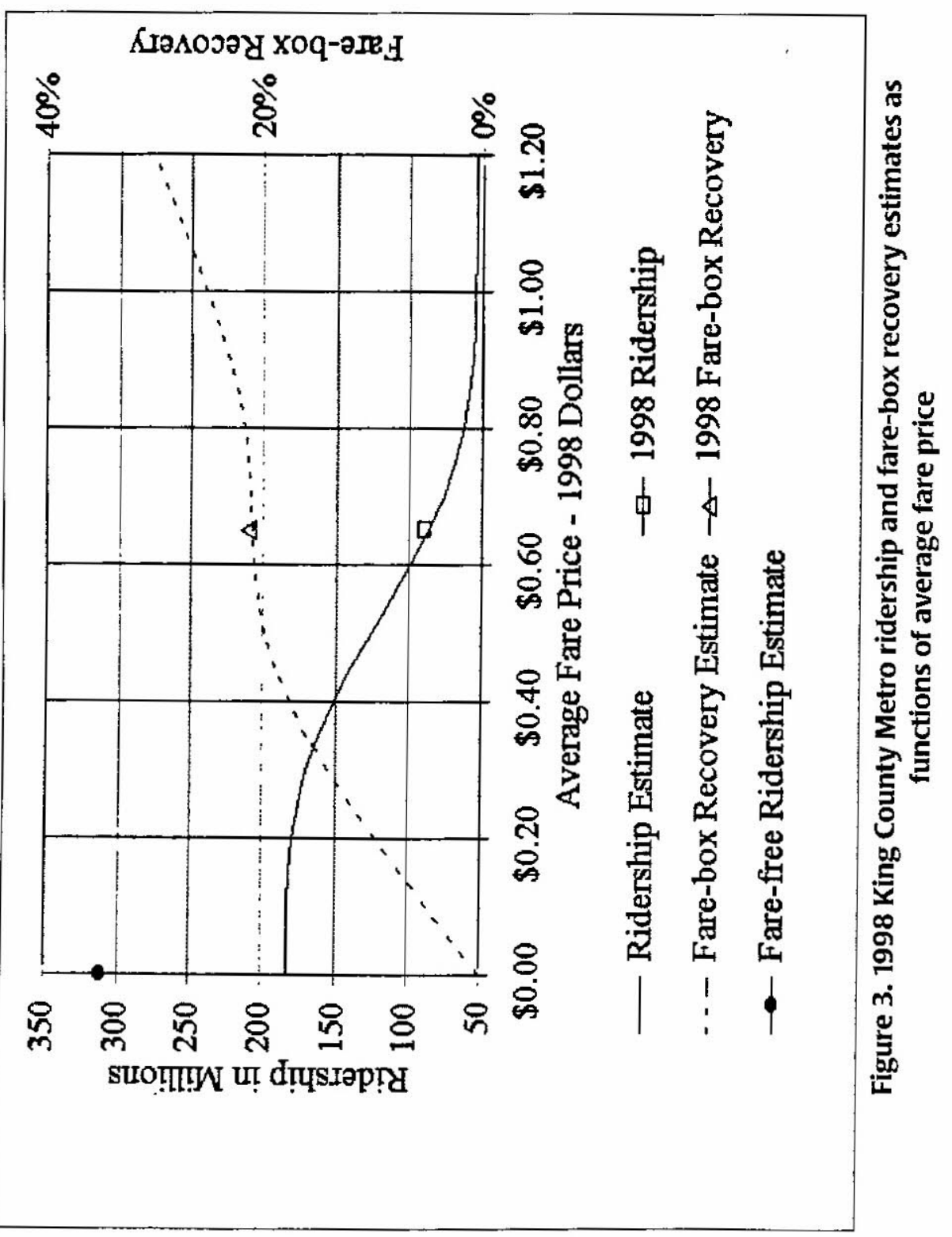


the average of the three major transit systems listed in Table 5 (5,387 v. 6,189 Rides/Seat/Year). Adopting a fare-free policy does not appear to have a significant capital impact. The operating cost would increase by 140 percent to 160 percent of the actual 1998 cost, depending on the savings realized by not collecting fares. If the average fare is increased to $\$ 1.25$, utilization and ridership would be reduced by about 38 percent. If the average fare is increased to $\$ 1.25$ and service is reduced to maintain the same utilization, ridership is reduced by 89.7 percent.

Kitsap Transit. Kitsap Transit serves 41 fixed routes in Kitsap County. The county is composed of small cities, rural communities, forests, and farmlands. Kitsap County is home to major navy facilities. It lies directly west and across Puget Sound from the Seattle metropolitan area and is served by four ferry routes. The 1998 base fare is $\$ 1.00$ per boarding; the average fare is $\$ 0.33$.

Figure 4 shows the ridership and fare-box performance estimate for Kitsap Transit. Actual 1998 ridership and operating costs are lower than the models would estimate. At a $\$ 0.33$ average fare price, the ridership potential is close to the maximum for charging fares: 4.8 million rides per year. Any increase in average fares would move performance to the steeper part of the ridership/average fare curve, with a resulting sharp decrease in ridership. This situation is illustrated in Figure 2 with the difference in the midpoint or constant arc elasticity with a fare increase and decrease. If the average fare price were to decrease to zero, the resulting ridership estimate would be 8.4 million rides per year.

Table 7 lists selected Kitsap Transit performance estimates. The table shows the utilization (rides per seat) for $\$ 0.00$ average fare is not high. Adopting a farefree policy does not appear to have a significant capital impact. If the average fare is increased to $\$ 0.65$, the utilization and ridership would be reduced by about 46 percent. If the average fare is increased to $\$ 0.65$ and service is reduced to maintain the same utilization, ridership would be reduced by 92.6 percent. Fare-box recovery improves with each fare increase, but this does not have much meaning because the ridership is so markedly reduced.

Mason Transit. Mason Transit serves eight deviated rural fixed routes in Mason County, an area of 961 square miles with a population of 48,300. A deviated fixed route is a fixed route with sufficient schedule margin so that limited 


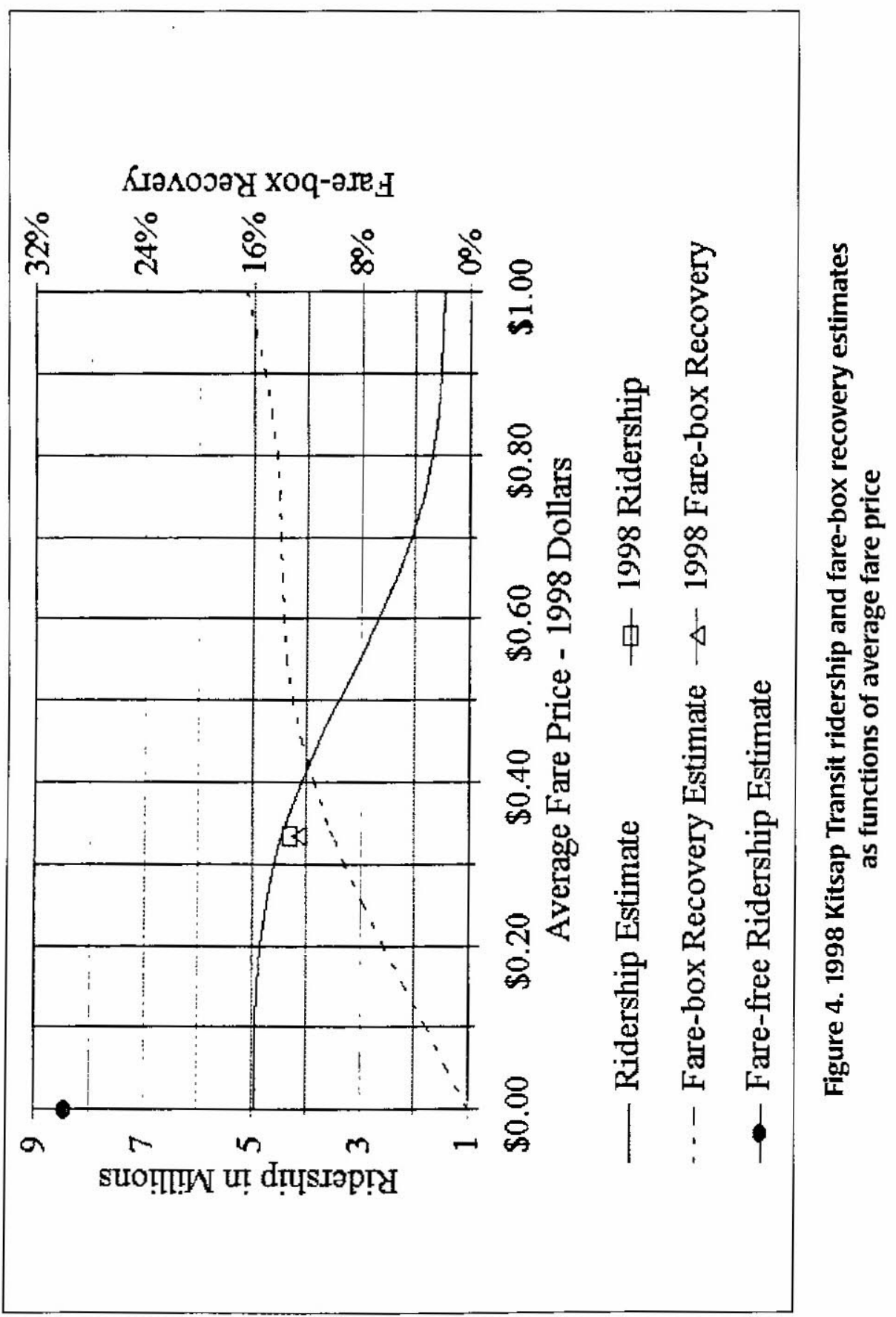




\begin{tabular}{|c|c|c|c|c|c|c|}
\hline \multicolumn{7}{|c|}{$\begin{array}{c}\text { Table } 7 \\
\text { KitsapTransit Performance Estimates with } \\
\text { Constant Service or Utilization }\end{array}$} \\
\hline $\begin{array}{c}\text { Average } \\
\text { Fares }\end{array}$ & $\begin{array}{l}\text { Service } \\
\text { (Seats) }\end{array}$ & Ridership & $\begin{array}{c}\text { Utilization } \\
(R / S) \\
\end{array}$ & $\begin{array}{c}\text { Operating } \\
\text { Cost }\end{array}$ & $\begin{array}{l}\text { Fare-box } \\
\text { Recovery }\end{array}$ & $\begin{array}{l}\text { Fare-Box } \\
\text { Revenue }\end{array}$ \\
\hline \multicolumn{7}{|c|}{ Constant Service (Seats) } \\
\hline$\$ 0.00$ & 3,120 & $8,427,351$ & 2,701 & $\$ 19,780,061$ & $0.00 \%$ & SO \\
\hline$\$ 0.33^{a}$ & 3,120 & $4,683,943$ & 1,425 & $\$ 12,619,817$ & $9.84 \%$ & $\$ 1,484,360$ \\
\hline$\$ 0.50^{b}$ & 3,120 & $3,412,277$ & 1,094 & $\$ 13,073,409$ & $1305 \%$ & $\$ 1,706,138$ \\
\hline$\$ 0.65$ & 3,120 & $2,524,913$ & 753 & $\$ 11,019,713$ & $13.71 \%$ & $\$ 1,527,264$ \\
\hline \$0.70 & 3,120 & $2,072,554$ & 664 & $\$ 10,404,247$ & $13.94 \%$ & $\$ 1,450,788$ \\
\hline$\$ 0.90$ & 3,120 & $1,529,790$ & 490 & $\$ 9,053,369$ & $15.21 \%$ & $\$ 1,376,811$ \\
\hline$\$ 1.10$ & 3,120 & $1,465,320$ & 470 & $\$ 8,876,577$ & $18.16 \%$ & $\$ 1,611,852$ \\
\hline$\$ 1.25$ & 3,120 & $1,463,668$ & 469 & $\$ 8,871,992$ & $20.62 \%$ & $\$ 1,829,585$ \\
\hline \multicolumn{7}{|c|}{ Constant Utilization } \\
\hline$\$ 0.65$ & 259 & 324,518 & 1,252 & $\$ 1,177,738$ & $17.91 \%$ & \\
\hline$\$ 1.25$ & 26 & 32,028 & 1,252 & $\$ 118,336$ & $33.83 \%$ & \\
\hline
\end{tabular}

a. 1998 actual average fare value.

b. Fare for first revenue maximum.

paratransit functions can be performed. The area includes one small city, Shelton. The county includes both Puget Sound and Hood Canal shorelines and part of the Olympic Mountain Range and National Park. Mason County economy has been timber based, but is giving way to a residential base. The mountains and shorelines make this an attractive retirement destination so there is an increasingly older population. The deviated rural fixed-route service is fare-free.

Figure 5 shows the performance estimate for Mason Transit. The actual 1998 ridership and operating costs are lower than the models would estimate. The fare-free operation of Mason Transit provides maximum ridership. The addition of fares to the general service routes (not the commuter or express routes) would result in at least a 41.2 percent decrease in ridership. The farebox recovery is so small that the cost of fare collection would not likely be covered in any reasonable fare price range.

Table 8 lists selected Mason Transit performance estimates. If the average fare is increased to $\$ 0.65$ and service is reduced to maintain the same utilization, ridership is reduced by 98.9 percent.

\section{Conclusions}

This study concludes that ridership efficiency provides an effective tool, 


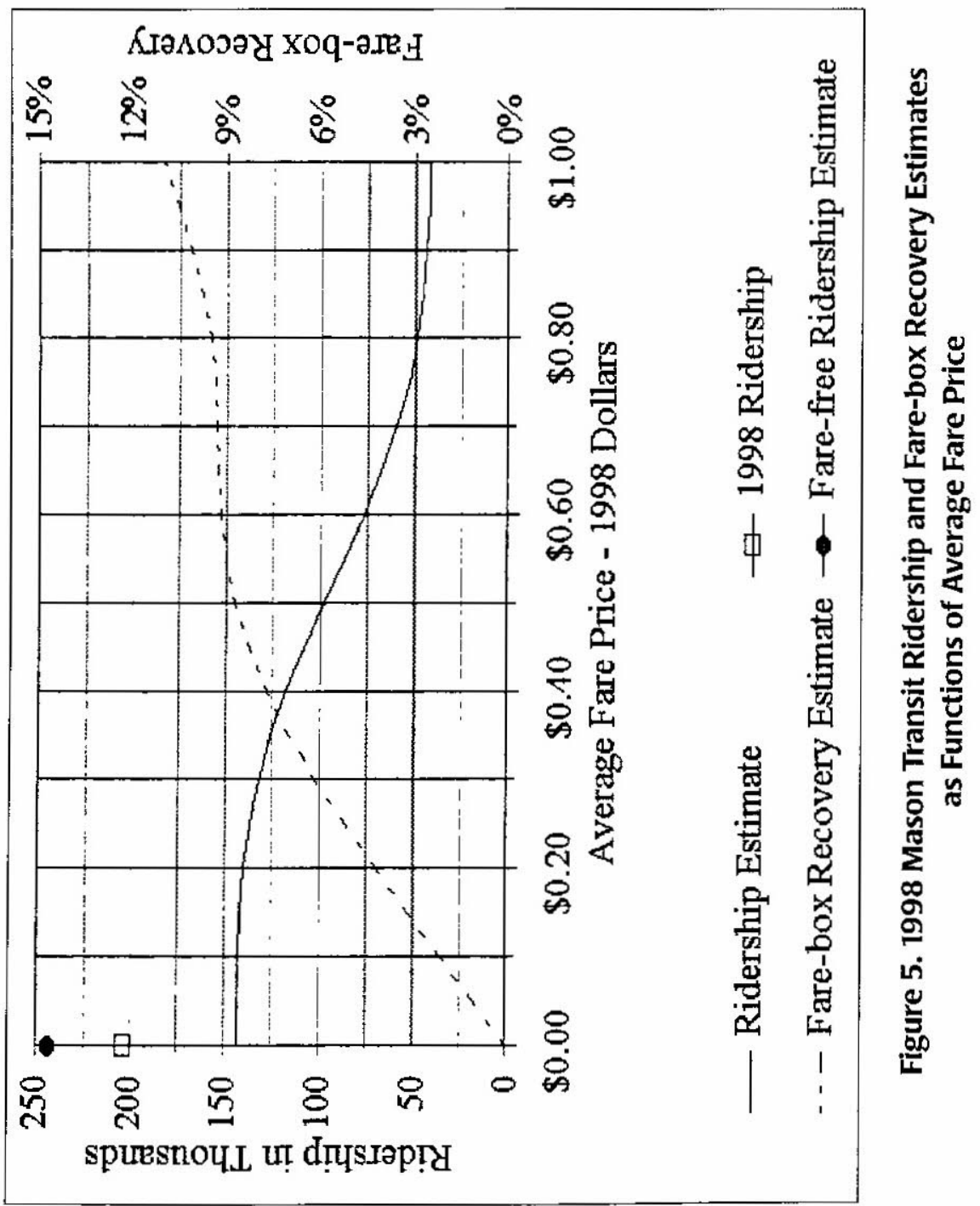




\begin{tabular}{|c|c|c|c|c|c|c|}
\hline \multicolumn{7}{|c|}{$\begin{array}{c}\text { Table } 8 \\
\text { Mason Transit Performance Estimates with } \\
\text { Constant Service or Utilization }\end{array}$} \\
\hline $\begin{array}{c}\text { Average } \\
\text { Fares }\end{array}$ & $\begin{array}{c}\text { Service } \\
\text { (Seats) }\end{array}$ & Ridership & $\begin{array}{c}\text { Utilization } \\
\quad R S\end{array}$ & $\begin{array}{c}\text { Operating } \\
\text { Cost }\end{array}$ & $\begin{array}{l}\text { Fare-box } \\
\text { Recovery }\end{array}$ & $\begin{array}{l}\text { Fare-Box } \\
\text { Revenue }\end{array}$ \\
\hline \multicolumn{7}{|c|}{ Constant Service (Seats) } \\
\hline$\$ 0.00^{\mathrm{a}}$ & 179 & 243,573 & 1,365 & $\$ 856,895$ & $0.00 \%$ & \$o \\
\hline$\$ 0.33$ & 179 & 128,538 & 720 & $\$ 639,416$ & $6.53 \%$ & $\$ 41,775$ \\
\hline$\$ 050^{b}$ & 179 & 98,624 & 553 & $\$ 566,355$ & $8.71 \%$ & $\$ 49,312$ \\
\hline$\$ 0.65$ & 179 & 67,911 & 380 & $\$ 477,387$ & $9.25 \%$ & $\$ 44,142$ \\
\hline$\$ 0.70$ & 179 & 59,902 & 336 & $\$ 450,724$ & $9.30 \%$ & $\$ 41,932$ \\
\hline$\$ 0.90$ & 179 & 44,215 & 248 & $\$ 392,202$ & $10.15 \%$ & $\$ 39,793$ \\
\hline$\$ 1.10$ & 179 & 42,352 & 237 & $\$ 384,544$ & $12.11 \%$ & $\$ 46,587$ \\
\hline$\$ 1.25$ & 179 & 42,304 & 237 & $\$ 384,345$ & $13.76 \%$ & $\$ 52,880$ \\
\hline \multicolumn{7}{|c|}{ Constant Utilization } \\
\hline$\$ 0.65$ & 3 & 2,529 & 1,364 & $\$ 11,608$ & $14.16 \%$ & \\
\hline$\$ 1.25$ & 2 & 1.974 & 1.364 & $\$ 9.544$ & $25.85 \%$ & \\
\hline
\end{tabular}

a. 1998 average fare value.

b. Fare for first revenue maximum.

based on service investment and community characteristics, for estimating ridership performance. Ridership efficiency as a function of fares is the probability that transit will be chosen by the transit-using population over other modes if fares are demanded and the fare price does not exceed a given value. This function is a biased cumulative normal distribution with average fare as the independent variable. The bias represents the condition where transit is used regardless of fare price.

Point, midpoint, and constant arc elasticities can be derived and calculated from ridership efficiency and average fare. This calculation shows that elasticities are functions of average fare price and are relevant only in that sense. The calculation suggests that a more direct way of estimating performance is from the ridership efficiency function of average fares.

Estimates for urban and small city transits show that if they were fare free, a very significant portion of the total trips in the service area could be captured by transit. With service remaining constant, utilization does not increase to the point where significant capital investment is required. If fares are increased, or in the case of rural transit, are imposed, ridership and utilization would decrease. This results in a very modest increase in fare-box recovery. The analysis of rural transit indicates that income from fares is probably not enough 
to pay for the fares collection. The reduced utilization would give rise to the "empty-bus" syndrome. A reduction in service to maintain utilization would result in a further decrease in ridership. The public benefit of transit lies in the increase of ridership that results from the capture of trips from other modes and the economic benefits of increased travel within the service area. This is achieved by the reduction of fares and the increase in service, or is maximized by adopting a fare-free policy.

Any large-scale capture of ridership from other modes can be done only through economic competition that is consistent with the public's perception of the transportation market. This study presents a measure of that perception with the variation of ridership efficiency over the regime of average fares in Washington State for 1998.

While this study is based on Washington State data, an examination of nationwide ridership efficiency might have wider application as a ridership estimator. Further, an examination of recent years would identify trends within the industry.

The transit systems studied in this article are either fare free or use conventional fare-box collection methods. The exception to this are the two transit systems that make wide use of passes and whose data points exceed the best-fit plot by more than two standard deviations. Examination of transit systems with combinations of revenue collection methods for the development of appropriate $B_{I}$ terms could provide insight into this aspect of transit operations.

\section{References}

Boyle, Daniel K. 1985. 64th Annual Meeting of the Transportation Research Board, Washington, DC.

Burkhardt, Jon. 1998. The economic impacts of rural transit services. TCRP Report 34. Transportation Research Board.

Corel Quattro Pro 6.0 Spreadsheet Program. 1996.

Hodge, David C., James D. Orrell III. and Tim R. Strauss. March 1994. Farefree policy: Costs, impacts on transit service, and attainment of transit system goals. WA-RD277.1. Final report. Olympia, WA: Washington State Department of Transportation. 
King. K. G., N. Garrick, and N. Ravishanker. January 1998. Long-term impact of free fare policy on bus ridership: A case study of WRTD bus service. Unpublished paper. Storrs, CT: University of Connecticut Departments of Civil and Environmental Engineering and Statistics.

LaBelle, S. J., and D. Fleishman. September 1997. Common issues in fare structure design. Chicago, IL: Chicago Transit Authority and Cambridge, MA: Multisystems, Inc.

Linsalata, J., and L. H. Pham. August 1991. Fare elasticity and its application to forecasting transit demand. Washington, DC: American Public Transit Association.

U.S. Department of Commerce. (1991). 1990 census of population and housing summary population and housing characteristics Washington. CPH-149, Washington, DC: Bureau of Census.

U.S. Department of Commerce. (2000). Statistical abstract of the United States:1999. Washington, DC: Bureau of the Census.

U.S. Department of Transportation. (1995) Transit profiles, for the 1994 national transit data base. Washington, DC: Federal Transit Administration.

U.S. Department of Transportation. (1999) 1998 data tables, national transit database. Washington, DC: Federal Transit Administration.

U.S. Department of Transportation (1999). Transit profiles, for the 1998 national transit data base. Washington, DC: Federal Transit Administration.

Washington State Department of Transportation. (1999). 1998 Summary public transportation systems in Washington State. Olympia WA: Public Transportation and Rail Division.

Washington State Office of Financial Management. (2000). 2000 population trends, Washington State, Olympia, WA. 